\title{
PROJETO ARQUEOLOGIA E EDUCAÇÃO: UM OLHAR PARA O PASSADO DA REGIÃO DE POÇOS DE CALDAS
}

Archaeology and Education Project: A look at the past of Poços de Caldas area

\author{
Solange Nunes de Oliveira Schiavetto ${ }^{1}$ \\ Ana Paula Gilaverte ${ }^{2}$ \\ Diego dos Santos de Andrade ${ }^{3}$
}

\section{RESUMO}

$\mathrm{O}$ artigo tem como intuito apresentar as principais ações de Projeto de Pesquisa sobre Arqueologia e Educação Patrimonial realizado na região sudoeste de Minas Gerais. O projeto tem como finalidade realizar pesquisas arqueológicas em Poços de Caldas e adjacências. Busca-se, a partir de metodologias advindas dos pensamentos arqueológico e antropológico, discutir as possibilidades de apreender a formação multicultural das populações humanas que hoje vivem na área foco da pesquisa. A produção material humana de tempos pretéritos, da História à Pré-História, é foco de nosso interesse, na medida em que possibilita aos investigadores produzir discursos que questionem a visão de um passado monocultural e de uma evolução unilinear da sociedade.

Palavras-chave: Arqueologia Pública, Educação Patrimonial, Multiculturalismo

\begin{abstract}
The article has as an intention to show the major actions of the Research Project about Archaeology and Patrimonial Education accomplished in Southern Minas Gerais. The project has as a purpose to achieve archaeological researches in Poços de Caldas and adjacencies. It seeks, from the methodology that comes from the archeological and anthropological thoughts, to discuss the possibilities of learning the multicultural formation of human populations that currently live in the research focused area. The human material production of ancient times, from History to Prehistory, is our main interest, as it makes it possible for the investigators to produce speeches that question the sight of a one-culture past and of a one-line evolution of society.
\end{abstract}

Keywords: Public archaeology, patrimonial education, multiculturalism

\footnotetext{
${ }^{1}$ Núcleo de Estudos e Pesquisas em Memória, Cultura e Educação/FAE/UEMG - Pós-doutoranda e Pesquisadora Colaboradora do Instituto de Filosofia e Ciências Humanas/UNICAMP - Bolsista do CNPq. Email: solange.schiavetto@gmail.com

${ }^{2}$ Professora de História da rede pública de ensino de Poços de Caldas- Ensino Médio - mestranda em Educação UFSCAR - E-mail: sofi.kirina@gmail.com

${ }^{3}$ Professor de História da rede Pública de Ensino de Poços de Caldas - Ensino Fundamental. E-mail: diego.st.andrade@gmail.com
} 


\section{RESUMEN}

Este artículo tiene como objetivo presentar las principales acciones del Proyecto de Investigación en Arqueología y Patrimonio de Educación celebrada en la región sur de Minas Gerais. El objetivo del proyecto es realizar una investigación arqueológica en Poços de Caldas y alrededores. Apunta, metodologías que surgen de los pensamientos arqueológicos y antropológicos, discutir las posibilidades de comprensión de la formación multicultural de las poblaciones humanas que viven ahora en el foco de la investigación. La producción de materiales de épocas pasadas humanos, desde la Prehistoria a la Historia, es el foco de nuestro interés, ya que permite a los investigadores producir discursos que cuestionan la visión monocultural de un pasado y una evolución unilineal de la sociedad.

Palabras clave: Arqueología Pública, Educación Patrimonial, Multiculturalismo

\section{Introdução}

Desde 2008 a Universidade do Estado de Minas Gerais/UEMG/Poços de Caldas tem desenvolvido discussões sobre as culturas do passado da região de Poços de Caldas. Tais atividades têm sido realizadas no contexto da sua Faculdade de Educação, Núcleo de Estudos e Pesquisas em Memória, Cultura e Educação, linha de pesquisa Memória, Cultura e Prática Docente. Gestado junto à criação do referido Núcleo de Pesquisa, o projeto "Arqueologia e Educação: um olhar para o passado da região de Poços de Caldas/MG" passou, desde o seu nascimento, por inúmeras modificações. Em linhas gerais, tem como intuito realizar pesquisas arqueológicas na região de Poços de Caldas. Os pesquisadores engajados nas questões propostas pelo projeto têm realizado discussões com alunos e colaboradores de outras instituições sobre a história oficial da região de Poços de Caldas (FERREIRA, 1996; LEMOS, 1904; MEGALE, 1990; MOURÃO, 1951; PRADO, 2000). É primordial compreender que em tal história não há a preocupação em evidenciar passados múltiplos. Pautada pelos escritos de memorialistas que, na maioria das vezes, evidenciam um passado unilateral, este discurso histórico tradicional não abre espaço para compreender as identidades indígenas e africanas, para ficarmos em apenas dois exemplos, como protagonistas no processo de formação cultural da área foco da pesquisa. As discussões dos primeiros anos da pesquisa renderam ao grupo a percepção de que é preciso buscar outras vias para abordar o passado. Ouvir as vozes das fontes orais e materiais tornou-se um caminho a ser seguido (CAVALCANTE, 2011).

Para a realização dos objetivos propostos pelo projeto, procuramos, primeiramente, compreender o histórico da Arqueologia e sua inserção nas questões sociais. Os pesquisadores 
e alunos inseridos nas discussões do projeto são levados a ponderar sobre o quanto a Arqueologia pode contribuir para abordar questões relativas à diversidade cultural (FUNARI, 1995b e 2001; FUNARI \& SCHIAVETTO, 2006; SCHIAVETTO, 2005 e 2007). A partir do histórico do pensamento arqueológico, podemos compreender como novas abordagens foram agregadas ao fazer arqueológico e de qual maneira os seus profissionais começaram a perceber que outros tipos de fontes poderiam ser agregados na construção dos passados. Ainda mais importante, podemos notar que o arqueólogo passou a ter a percepção de que o passado não encerra uma verdade escondida a ser desvendada por métodos rígidos de análise. A ideia de que os pesquisadores extraem do passado apenas discursos passou a fazer sentido para a maioria dos arqueólogos no Brasil e no mundo (FUNARI, 1994 e 1995a; OLIVEIRA, 2005). Desta forma, podemos argumentar que as metodologias utilizadas em nossas pesquisas no presente projeto agregam elementos da história (História Oral) e da Antropologia (discussões teóricas sobre identidade, etnografia/trabalho de campo), buscando produzir um fazer arqueológico pautado em múltiplas visões.

Com o advento de novas abordagens em Arqueologia o arqueólogo passou a perceber a importância de repensar a sua posição como cientista que produz discursos sobre as identidades dos agrupamentos humanos. Esta ciência também deu uma guinada em suas concepções sobre o papel social do arqueólogo, o que fez brotar, aos poucos, a consciência de que o cientista que lida com a cultura material do passado deve voltar os seus olhos ao presente. Desta forma, uma Arqueologia caracterizada como "Pública" tem como intuito, na atualidade, suscitar a reflexão do papel social do arqueólogo, sobretudo deste inserido em processos educativos (ALMEIDA, 2005; CURY, 2006; FUNARI \& PELEGRINI, 2006). É nesta vertente da Arqueologia Pública que nosso trabalho se insere.

Neste artigo descreveremos os trabalhos realizados em 2012, com o auxílio da Lei Municipal de Incentivo à Cultura de Poços de Caldas e o incentivo da Alcoa Alumínio S.A. O projeto conta, atualmente, com dois pesquisadores colaboradores da Fundação Araporã, dois professores de História da rede pública de ensino de Poços de Caldas, uma aluna bolsista e uma aluna voluntária. Em 2012, centramos atenção nas terras pertencentes aos municípios de Poços de Caldas, Botelhos e Caldas. Tais municípios são importantes para as atividades do projeto por revelarem, em sua história oficial, mesmo que de forma distorcida ou insuficiente, a presença de povos culturalmente diversificados na região: africanos e indígenas. No primeiro momento da pesquisa, centramos atenção em Caldas, por termos coletado informações orais sugerindo a presença de sítios arqueológicos na região. 
O município de Caldas está localizado na Região Sul de Minas Gerais, é um dos mais antigos entre os pertencentes ao Planalto do Alto Rio Pardo, sendo Poços de Caldas a maior cidade desta micro região. Caldas tornou-se freguesia em 1813, com o nome de Rio Verde das Caldas. Poços de Caldas era considerada parte de Caldas até o final do século XIX, recebia a denominação de Caldas, sendo chamada de Campos das Caldas em fins do século XVIII (PIMENTA, 1998).

As publicações caldenses evidenciam que a região da Pedra Branca, onde se localiza o município, passou a ser ocupada pela frente colonial com o declínio da atividade mineradora em Vila Rica, São João Del Rey e arredores, devido a busca de terras para a atividade agropecuária. (MEGALE, 1990; PIMENTA, 1998)

A fazenda dos Bugres foi comprada por volta de 1780, iniciando-se pouco depois o povoamento que daria origem ao arraial. O nome da fazenda é uma referência a potes de barro e outros objetos encontrados na localidade que indicavam que aquela região havia sido habitada por indígenas em períodos anteriores. Relatos afirmavam que os objetos deveriam ter sido dos indígenas "tapuias". Os artefatos estavam localizados próximo ao ribeirão que ganhou a mesma nomenclatura: "Ribeirão dos Bugres".

$\mathrm{Na}$ tradição oral, o município de Caldas era ocupado por "bugres e tapuias" no período da chegada dos colonizadores. Algumas pessoas afirmam ainda a existência em Caldas de indivíduos que descendiam dos grupos nativos. Todavia, os livros sobre a história da cidade não corroboram a oralidade dos caldenses mais velhos, parcela considerável de moradores da zona rural. Os escritos sobre a história do município afirmam a existência do indígena somente até a ocupação e o início do povoamento, tendo estes sido expulsos logo no contato com os bandeirantes (MEGALE, 1990, PIMENTA, 1998). Nestas obras, não é trabalhada a permanência do nativo no período de formação do arraial, nem mesmo a possibilidade desta continuidade e o respectivo cruzamento destes com brancos e negros.

O livro mais difundido sobre a história do município, de autoria de Reinaldo Pimenta, cita os "índios tapuias" como primeiros habitantes da região. Segundo Pimenta, havia um acampamento de uma pobre tribo de bugres nas proximidades de onde seria construído o arraial. Prossegue afirmando que "a conquista da região aos seus primitivos donos, o patrício caiapó, sucedeu ao recuo das populações indígenas, tangidas rumo a oeste pela 'onda civilizatória"' (PIMENTA, 1998:12).

O indígena não é citado depois da segunda página dos livros da história do 
município, fato também recorrente nas obras sobre a história de outras cidades, analisadas por arqueólogos e historiadores quando em busca de informações sobre o elemento indígena no passado das mesmas, ainda que a tradição oral e o material arqueológico apontem o contrário (FUNARI, 2001; CAVALCANTE, 2011; SCHIAVETTO \& SOUZA, 2008).

No tocante à população negra, Reinaldo Pimenta também não se ateve a importância desta na construção de Caldas, seja no aspecto político, cultural ou econômico. Sua obra tem foco nos "desbravadores", no colonizador, no fazendeiro. Se a população indígena desaparece na segunda página de seu livro, para a população negra o autor foi bem mais econômico.

Embora não apareçam nos livros, os negros enriqueceram não apenas a economia local, mas, sobretudo, a cultura. Não apenas em citações pontuais e evidentes, como nas festas, sendo exemplo a congada (que inclusive conta com a entrada dos Caiapós), na religiosidade, na cultura material ou na linguagem, de fato, em todo aspecto social e cultural, seria impossível abordar Caldas e Poços de Caldas sem destacar a importância da população negra.

No que tange aos indígenas, a possível escassez de fontes poderia ser uma explicação para sua ausência na história local. É evidente a primazia das fontes escritas, muitas vezes adotadas com exclusividade por biógrafos, historiadores e jornalistas. Mesmo sabendo-se da importância de outras fontes, elas acabam não sendo utilizadas de modo satisfatório. A história de diversos municípios é contada apenas pelas fontes documentais. Poços de Caldas e região não fogem a esta regra. Assim, sendo esta a "história dos vencedores", não há registros escritos referentes à população indígena ou negra no município de Caldas.

Pode-se considerar outra questão: este ocultamento aconteceria para se evitar trazer ao presente discussões relativas a confrontos, tomada de terras e/ou violência? Questão esta que pode ser aprofundada, porém sem respostas até o momento. Neste sentido, está enunciado um silêncio que carece de pesquisas e acreditamos que as investigações arqueológicas podem trazer elementos importantes na constituição históricocultural de Poços de Caldas e adjacências.

\section{Ação educativa: atividade inaugural do projeto}


O desenvolvimento do projeto possibilitou a realização de Ações Educativas em escolas públicas e na universidade (UEMG/Poços de Caldas). A primeira parte das Ações Educativas foi realizada em maio de 2012, nas dependências da Universidade do Estado de Minas Gerais, Autarquia Municipal de Ensino de Poços de Caldas. O evento inaugurou, para as atividades de 2012, os trabalhos do projeto de pesquisa "Arqueologia e Educação". Para o referido evento contamos com a presença de dois pesquisadores da Universidade Estadual Paulista “Júlio de Mesquisa Filho", UNESP/Campus de Araraquara. O Prof. Dr. Robson Antonio Rodrigues, arqueólogo, membro do Centro de Estudos Indígenas Miguel Angel Menéndez - UNESP/Araraquara e da Fundação Araporã, que proferiu a palestra “A pesquisa arqueológica no contexto brasileiro". A Profa. Dra. Dulcelaine Lopes Nishikawa, socióloga, doutoranda do Programa de Pós-Graduação em Sociologia da UNESP/Araraquara, que ministrou a oficina "Educação Patrimonial".

O evento contou com a presença de alunos de quatro turmas do curso de Pedagogia da UEMG, uma turma de alunos da Educação de Jovens e Adultos da Escola Pio XII, alunos do cursinho Educafro, além de participantes interessados na temática arqueológica e patrimonial. Dentre os participantes havia professores de História e Geografia das redes pública e privada da educação em Poços de Caldas. O evento totalizou 169 participantes. Houve a possibilidade de participação das duas atividades (palestra e oficina), pois o palestrante e a oficineira fizeram suas apresentações duas vezes, a fim de abarcar todo o público interessado no evento. Houve certificação de 4 h/a de participação das atividades, que se iniciaram às 19:00h e finalizaram às 22:30h.

O professor Robson e a professora Dulcelaine participaram no mesmo dia do Jornal do Meio Dia na TV Plan, no qual discorreram sobre pesquisas arqueológicas, Educação Patrimonial, e a importância das pesquisas voltadas para a região de Poços de Caldas. A participação foi um convite do jornalista e âncora do Jornal do Meio Dia, Roberto Tereziano. A palestra e a oficina conduziram os participantes a uma reflexão sobre o fazer arqueológico e a possibilidade de apreensão do patrimônio cultural de Poços de Caldas, com um olhar para o material arqueológico já documentado na região.

\section{Etapas de levantamento arqueológico}

Os levantamentos realizados estão levando em consideração as informações orais já obtidas desde 2008, além de coletar mais informações nas cidades vizinhas a Poços de Caldas. 
As etapas já realizadas apontaram para um grande potencial arqueológico da área escolhida para a pesquisa. A primeira etapa de campo contou com duas frentes de trabalho: busca por informações orais e caminhamentos em áreas pré-selecionadas a partir de estudo das cartas topográficas.

\section{Primeira etapa de levantamento arqueológico}

Para a primeira etapa de campo (caminhadas), selecionamos uma área contida na carta do IBGE de Caldas (escala 1:50.000), próxima ao perímetro urbano do referido município. Caldas está em área banhada pelo Rio Verde, tributário do rio Pardo. O Ribeirão dos Bugres, por sua vez afluente do Rio Verde, também banha as terras de Caldas. Foi nestes dois rios (Rio Verde e Ribeirão dos Bugres) que iniciamos os nossos trabalhos de levantamento de campo. Seguindo de Poços de Caldas a Caldas, pela BR 459, passa-se pela ponte do Rio Verde, que está na confluência deste rio com o Ribeirão dos Bugres. Este foi um dos pontos de referência para o nosso caminhamento na área. Elegemos, para nossas caminhadas, as áreas da margem direita do rio Verde e esquerda do Ribeirão dos Bugres. No Ribeirão dos Bugres, partindo da entrada do município de Caldas até a foz deste rio há cerca de $4 \mathrm{~km}$. No Rio Verde, desde o seu encontro com o Ribeirão dos Bugres até uma ponte que o atravessa na estrada que vai para Pocinhos há cerca de $5 \mathrm{~km}$. Nesta região há pequenos sítios e fazendas.

No momento de nossas pesquisas, muitas propriedades estavam com o solo utilizado para pastagem, o que dificultou a visualização do solo para encontrar possíveis vestígios de material arqueológico. Porém, realizamos caminhamentos e observação do solo em áreas nas quais a terra estava exposta. Quando encontrávamos solo de difícil visualização, optávamos pelas conversas com os moradores a fim de averiguarmos se vestígios arqueológicos já foram encontrados na região. O material arqueológico é bem conhecido dos moradores, sobretudo os mais antigos. Mesmo que na maioria das vezes não saibam da relevância patrimonial de tais vestígios, sabem que são objetos que representam um passado que muitos dos seus familiares testemunharam. É fácil encontrar casos que as pessoas tenham em casa algum material arqueológico encontrado durante os trabalhos na lavoura ou em momentos de construção. Além disso, muito da história local reside na memória das pessoas ou em escritos oficiais, como livros de memorialistas ou documentos. Desta forma, o material arqueológico encontrado auxilia na criação de um quadro pretérito que faz sentido para as pessoas, na 
medida em que elas se sentem ligadas àquelas peças e suas histórias.

Uma das histórias que coletamos no Sítio São Bartolomeu, margem esquerda do Ribeirão dos Bugres, foi que há 58 anos,quando o sítio era uma fazenda maior, próximo a um córrego, os filhos do fazendeiro encontraram um pote de barro com alça. Um dos filhos do fazendeiro, hoje proprietário de uma parte das terras, o referido Sítio São Bartolomeu, levou parte da equipe até o local onde encontraram o pote. No entanto, não foi possível visualizar o solo, pois, hoje, a propriedade é, em sua maioria, área de pastagem. Mesmo não tendo encontrado vestígios de material arqueológico no local, a história é interessante, pois atesta que a região foi habitada por diferentes culturas no passado e que os vestígios de tais habitações podem ainda ser encontrados.

O levantamento próximo à margem esquerda do Ribeirão dos Bugres rendeu alguns achados isolados (ocorrências arqueológicas) que podem não representar antigas ocupações, mas evidenciam o potencial arqueológico da área que escolhemos para iniciar a pesquisa. A vistoria na área que antes era a Fazenda do Ribeirão dos Bugres, local onde há informações orais de que antigamente havia um "cemitério indígena", evidenciou algumas ocorrências de fragmentos de potes. No entanto, a conversa com os atuais moradores das pequenas propriedades do local não revelou algo significativo para nossas pesquisas.

$\mathrm{Na}$ margem direita do Rio Verde iniciamos as atividades com observação de perfil. Realizamos caminhadas ao longo de sua margem procurando pontos onde houvesse fácil acesso às pequenas propriedades e aos locais com terra arada ou com cultivo que facilitasse a visualização do solo. Utilizando esta metodologia de abordagem, chegamos a um sítio arqueológico. O sítio está implantado em área que hoje é dividida por duas propriedades. Uma delas é a Fazenda Rio Verde, a outra é de propriedade de uma família em Caldas, da qual pegamos as informações para futuros contatos. No momento da descoberta do sítio, uma das partes estava sendo utilizada para plantação de batata doce e na outra havia girassol. O sítio caracteriza-se por uma variedade muito grande de fragmentos de cerâmica, louça e material construtivo mais recente. Há, pelo menos duas, concentrações bem visíveis de material arqueológico. Somente escavações aliadas a um resgate da memória e da história do local pode nos revelar mais detalhes sobre o sítio. No entanto, alguns elementos do material cerâmico nos levam a crer que se trata de uma ocupação recente, ligada ao período histórico, com influências da cultura africana e indígena. Em nossa primeira visita ao local do sítio arqueológico, na ocasião de sua descoberta, encontramos um cachimbo modelado em cerâmica. Após algumas buscas por material bibliográfico e conversas com especialistas em 
cachimbos arqueológicos, constatamos que se trata de um cachimbo africano, e não indígena. Porém, no local, encontramos bordas de potes com decoração e pintura geralmente associadas aos indígenas. O sítio arqueológico será por nós registrado junto ao Instituto de Patrimônio Histórico e Artístico Nacional. Pretendemos elaborar um projeto de escavação e ações educativas para prosseguirmos as pesquisas a partir do segundo semestre de 2013.

A descoberta deste sítio sugeriu a busca por trabalhos arqueológicos que abordem cachimbos africanos e indígenas. As pesquisas realizadas sobre cachimbos encontrados em sítios arqueológicos brasileiros referem-se ao período pré-contato em geral associados a algumas tribos indígenas como os tupis - guarani e os kaiapós. No período colonial, os cachimbos estão associados a escravos, ex-escravos e a elite brasileira. Há, também, cachimbos do período Neobrasileiro que agregam elementos africanos e indígenas.

A utilização do cachimbo tanto indígena quanto africano aponta para o aspecto do uso cotidiano, cerimonial e no período colonial como forma de contestação social entre os escravos. Os cachimbos pré-coloniais indígenas utilizados em cerimônias assumiam a conotação do sagrado em rituais de cura e rituais funerários, em danças e cantos, (FACCIO, 2009; MARQUES, 2009). No cotidiano, eram utilizados para o cultivo do cará e milho, no cozimento de certos tipos de alimentos como carne, pescado e galinha (MARQUES, 2009).

Entre os guaranis, os cachimbos conhecidos como petynguá eram utilizados em rituais de saudação, nas cerimônias de nominação de crianças, nas festas dedicadas ao milho novo, nas terapias de cura e para a recepção de visitantes. Em geral, eram confeccionados em antiplástico com argila tendo decoração incisa com motivos diagonais; de madeira ou taquara. Relatos de viajantes do período colonial, como André Thevet e Jean de Lery atestam o uso do cachimbo entre as tribos indígenas, "os índios recebiam o "espírito da santidade" ao sorver o fumo, e, da mesma maneira, ao incorporar sua fumaça através de sopros do Cariba" (MARQUES, 2009:16).

No período colonial, o "ato de fumar" e o uso do cachimbo permitiam aos escravos, urbanos ou rurais, uma fuga da rotina de trabalho e representava uma estratégia de resistência à dominação imposta. O seu uso se tornou tão peculiar, que virou um traço marcante na cultura negra: "o escravo e o seu cachimbo" (AGOSTINI, 2009). A prática de fumar era amplamente difundida entre homens e mulheres, existindo casas de comércio, secos e molhados que tinham entre seus produtos a venda de artigos exclusivos para fumo e a importação de canudos vindos da África para este fim.

Os elementos decorativos apresentados em alguns cachimbos africanos sugerem a 
interligação da representatividade de traços de identidade étnica. Alguns autores apontam que as decorações encontradas nestes cachimbos podem estar associadas às escarificações: marcas tribais de iniciação ou pertença a uma comunidade (AGOSTINI, 2008). Em analogia, estas escarificações remeteriam à cultura "mãe" a África.

No período do tráfico negreiro, após a captura na África, negros de etnias diversas eram entregues ao contrabando de escravos sendo vendidos no Brasil. Pela convivência com outros grupos étnicos, teria ocorrido uma nova ressignificação e a formação de novos elos culturais entre grupos negros que antes eram rivais e que se uniram por terem em comum o branco/dominador como o inimigo e a ordem estabelecida a ser rompida.

Alguns cachimbos encontrados em sítios arqueológicos que apontam para o período Neobrasileiro identificam traços indígenas e africanos, apontando o local como refúgio de quilombolas no qual não concentravam apenas negros, mas também, como afirmam fontes bibliográficas, congregavam indígenas, ex-escravos e brancos pobres, todos os que não estavam inclusos na ordem estabelecida. Apesar de o cachimbo encontrado ser apenas um dos diversos elementos a serem dignos de estudo aprofundado no sítio, ele pode nos apontar o caminho que devemos seguir para termos uma melhor compreensão do rico panorama histórico-cultural que contribuiu para a formação do que hoje é o município de Caldas. A compreensão dos elementos culturais do sítio arqueológico encontrado também possibilitará inserir a história da região em um contexto mais amplo, no qual foram formadas culturas diversificas no sul e sudoeste do Estado de Minas Gerais.

\section{Segunda etapa do levantamento arqueológico}

A segunda etapa de campo do projeto foi iniciada com o objetivo de averiguar algumas informações orais sobre prováveis locais de sítio arqueológico. Fomos à São Pedro de Caldas, no Bairro Botafogo, buscar informações sobre o que as pessoas da região chamam de "ocas de índios". Trata-se de abrigos sob rocha, locais prováveis de se encontrar vestígios indígenas por se constituírem, no passado, em acampamentos sazonais para caça. Na Fazenda São Pedro há vários abrigos sob rocha. Fizemos vistoria em três abrigos e não encontramos vestígios arqueológicos. Porém, como é região de potencial arqueológico, cheia de abrigos e próxima ao rio Pardo, intensificaremos o levantamento e a coleta de informações orais em etapas futuras.

Realizamos caminhamentos na margem direita do Rio Pardo, margeando a rodovia 
MG 28 (BR 146), sentido Botelhos. Nesta margem, caminhamos cerca de 6 quilômetros, entramos em algumas propriedades e fizemos observação do solo. Não encontramos vestígios de material arqueológico e a conversa com os moradores da região não revelou pontos importantes a serem vistoriados. Outra equipe foi até São Gonçalo de Botelhos, distrito do município de Botelhos, a fim de vistoriar uma área com informações sobre alguns abrigos. Havia informações sobre uma lâmina de machado encontrada há algumas décadas. A vistoria no local revelou algumas ocorrências arqueológicas em dois abrigos. Trata-se de fragmentos de quartzo lascado.

Nesta etapa também fomos a Santana de Caldas a fim de chegarmos mais próximos da confluência do Rio Verde com o Rio Pardo. Desta forma, fizemos vistoria neste local, na margem esquerda do rio Pardo. Observamos as margens direita e esquerda do rio Verde, mas não encontramos vestígios arqueológicos e também não coletamos informações relevantes para a pesquisa arqueológica.

\section{Terceira etapa de levantamento arqueológico}

A terceira e última etapa de campo de 2012 foi idealizada levando em consideração a necessidade de intensificação das caminhadas e da busca de informação oral mais próximo ao Rio Pardo. Consideramos que seria interessante dar prosseguimento à vistoria na área contida na carta topográfica de Caldas (Escala 1:50.000), entre a confluência do rio Pardo e do rio Verde, subindo o primeiro rio até área próxima à ponte do bairro Botafogo. Tal ponte está na estrada que liga Caldas e São Pedro de Caldas. Botafogo é um bairro pertencente a São Pedro de Caldas. Nesta terceira etapa de campo, ao analisarmos a carta topográfica e fotos aéreas, elegemos a margem direita deste trecho do rio Pardo para caminhadas.

Além das caminhadas, realizamos entrevistas com moradores do Bairro Botafogo e visitamos as obras da Pardo Energia S.A. Conversamos com o engenheiro responsável pelas obras de uma Pequena Central Geradora $(\mathrm{CGH})$ que está sendo construída no rio Pardo, próximo ao Bairro Botafogo. Ele nos informou que as vistorias ambientais foram realizadas pela A.S. Ambiental. Tais relatórios são importantes, uma vez que contemplam os laudos arqueológicos. No momento oportuno, entraremos em contato com o setor de meio Ambiente da empresa a fim de ter acesso aos pareceres e relatórios da instalação da CGH Pardo.

Nesta etapa da pesquisa, encontramos um fragmento polido, possivelmente uma mão de pilão. $\mathrm{O}$ fragmento foi encontrado na margem direita do rio Pardo, na confluência com o 
córrego São Pedro. As vistorias na margem direita do rio Pardo também renderam o achado de outra ocorrência arqueológica.

As ocorrências arqueológicas, embora não configurem uma ocupação humana passível de escavação e pesquisa mais detalhada, são importantes indicadores do potencial arqueológico da região. No caso do fragmento da mão de pilão e dos cacos de cerâmica, em especial, sugerem a presença no entorno de populações sedentarizadas, que praticavam agricultura. Desta forma, os resultados do trabalho de campo somados às informações orais coletadas evidenciam um grande potencial arqueológico para a região de Poços de Caldas. Tais pesquisas são de grande importância para ações patrimoniais em âmbito escolar e extraescolar.

\section{Ações educativas em escolas públicas em Poços de Caldas}

Como parte do desenvolvimento das pesquisas, foram realizadas ações educativas em duas escolas públicas de Poços de Caldas. A atividade teve como finalidade divulgar os trabalhos que estão sendo realizados e, sobretudo, levar para as escolas reflexões sobre a Arqueologia e suas contribuições para uma melhor compreensão das identidades locais e suas histórias. Uma parte da equipe do projeto, composta pela pesquisadora Dra. Dulcelaine Lopes Nishikawa, coordenadora das atividades nas escolas, três alunas do curso de Pedagogia da UEMG, uma aluna de Ciências Sociais da UNESP/Araraquara e uma professora de História do Ensino Médio, realizou, em duas escolas, uma oficina de sensibilização cultural. O objetivo foi levar aos alunos um pouco da História Cultural de Poços de Caldas e um contato com o material arqueológico (lítico lascado, lítico polido e cerâmica). A equipe ressaltou aos alunos a possibilidade de encontrar na região vestígios arqueológicos que contem a História a partir de um outro ponto de vista, não pautado pelas fontes oficiais e pelos livros didáticos. Os resultados das Ações Educativas foram apresentados pela coordenadora das atividades, em forma de relatório, e nortearão nossas investidas futuras em escolas de Poços de Caldas e região.

\section{Primeiros resultados}

Os trabalhos realizados em 2012 evidenciaram a necessidade de se fazer estudos sistemáticos sobre a Arqueologia da região e a história local. Há muitos trabalhos 
historiográficos de memorialistas sobre Poços de Caldas e Caldas, dois importantes municípios do sudoeste de Minas Gerais. Porém, em todos eles a herança indígena e africana na constituição cultural da região é pouco relevante. Acreditamos que as pesquisas arqueológicas auxiliarão em uma reconstrução discursiva multicultural, em vez de monocultural. Tal reconstrução é crucial para repensarmos ações educativas que suplantem a forma tradicional de encararmos as histórias locais, que devem ser contadas sempre no plural. A descoberta de ocorrências arqueológicas isoladas e de um sítio arqueológico em Caldas é um importante passo para pesquisas arqueológicas futuras. O relatório dos trabalhos efetuados será encaminhado ao IPHAN, a fim de cadastrar o sítio arqueológico encontrado em Caldas. Solicitaremos permissão para realizar escavações neste sítio. Solicitaremos verba para órgãos de fomento à pesquisa a fim de realizar os trabalhos de escavação. Ainda, a continuidade do projeto visa realizar mais etapas de levantamento nas áreas que não pudemos vistoriar e, ao mesmo tempo, continuar a busca por informações orais. Realizaremos estudos dirigidos para as temáticas da Arqueologia de Minas Gerais e das regiões sul e sudoeste, sobretudo, buscando trabalhos arqueológicos que descrevam os contextos de interação entre indígenas, africanos e colonizadores europeus. As ações educativas nas escolas terão continuidade também em 2013 e buscarão ampliar o número de escolas atendidas pela iniciativa do projeto, inclusive com alunos do Ensino Fundamental e Médio sendo contemplados com bolsa BIC Júnior.

\section{Referências bibliográficas}

AGOSTINI, Camila. Cultura material e a experiência africana no sudeste oitocentista: cachimbos de escravos em imagens, histórias, estilos e listagens. Revista Topoi, v.10. n.18, jan-jun. 2009, p.39-47.

AGOSTINI, Camilla. Resistência Cultural e Reconstrução de Identidades: Um Olhar Sobre a Cultura Material de Escravos do Século XIX. Revista de História Regional, (3): 2, 2008, pp.113-137.

ALMEIDA, Paulo Araújo. Arqueologia em Conceição dos Ouros-MG. Gráfica e Editora Amaral - Pouso Alegre/MG, 2005.

CAVALCANTE, Thiago L. V. Etno-história e história indígena: questões sobre conceitos, métodos e relevância da pesquisa. História (São Paulo) v. 30, n. 1, p. 349-371, jan/jun 2011.

CURY, Marília X. Para saber o que o público pensa sobre Arqueologia. In: Revista Arqueologia Pública, NEE/UNICAMP, pág. 31-48:2006. 
FACCIO, Neide Barrocá. DI BACO, Hiuri Marcel. Cachimbo guarani do sítio arqueológico de macaco, estado de São Paulo. In: Revista Tópos, Volume 3, Número 2 - Presidente Prudente, Dezembro de 2009.

FERREIRA, J. Um hectare na história de Poços de Caldas. 11 a ed. Poços de Caldas: Gráfica Brasil, 1996.

FUNARI, Pedro P.A. Arqueologia Brasileira: visão geral e reavaliação. In: Revista de História da Arte e Arqueologia, 1, 23-41, 1994.

FUNARI, Pedro P.A. A hermenêutica das ciências humanas: a História e a teoria e práxis arqueológicas. In: Revista da Sociedade Brasileira de Pesquisa Histórica, 10, 3-9, 1995a.

FUNARI, Pedro P.A. A cultura material e a construção da mitologia bandeirante: problemas da identidade nacional brasileira. Idéias, 2,1, 29-48, 1995 b.

FUNARI, Pedro P.A. Os desafios da destruição e conservação do patrimônio cultural no Brasil. In: Trabalhos de Antropologia e Etnologia. Porto, 41:23-32, 2001.

FUNARI, Pedro P.A. \& PELEGRINI, Sandra C.A. Patrimônio Histórico e Cultural. Rio de Janeiro, Jorge Zahar Editor, 2006.

FUNARI, Pedro P.A. \& SCHIAVETTO, Solange N.O. Pesquisas Arqueológicas na região central do Estado de São Paulo. In: Revista de História da Arte e Arqueologia, IFCH/UNICAMP, 2006.

LEMOS, Pedro Sanches. As águas Thermaes de Poços de Caldas. Belo Horizonte: Imprensa Official do Estado de Minas Gerais, 1904.

MARQUES, Roberta P. Cachimbos guarani: uma interpretação etnoarqueológica. Trabalho de Conclusão de Curso: História, Universidade Federal do Rio Grande do Sul, Nov.

2009.

MEGAlE, Nilza B. Memórias Históricas de Poços de Caldas. Poços de Caldas: GSC Assessoria de Comunicação Empresarial, 1990.

MOURÃO, Mário. Poços de Caldas: Síntese Histórico-Social. $2^{\mathrm{a}}$ ed. São Paulo. Oficinas Gráficas de Saraiva, 1951.

OLIVEIRA, Jorge E. Por uma Arqueologia socialmente engajada: Arqueologia Pública, Universidade Pública e Cidadania. In: FUNARI, Pedro P.A., ORSER JR., Charles E. \& SCHIAVETTO, Solange N. O. Identidades, discurso e poder: estudos da Arqueologia Contemporânea. Fapesp/Annablume, Pag. 117-132, 2005.

PIMENTA, Reinaldo de Oliveira. O povoamento do Planalto da Pedra Branca - Caldas e região. Complemento: Colcha de Retalhos / Marta Amato. São Paulo: s. ed. 1998.

PRADO, A. História da Mineração no planalto de Poços de Caldas. Poços de Caldas: Gráfica Poços de Caldas, 2000. 
SCHIAVETTO, Solange N. O.; SOUZA, Vera L. Projeto de Pesquisa: Memória e cultura material: Estudos de Educação Patrimonial em Poços de Caldas/MG. Universidade do Estado de Minas Gerais: Poços de caldas, 2008.

SCHIAVETTO, Solange N.O. Arqueologia Regional e Educação: propostas de estudos sobre um "passado excluído" de Araraquara/SP. Tese de Doutoramento, Campinas, IFCH/UNICAMP, 2007.

SCHIAVETTO, Solange N.O. A questão étnica no discurso arqueológico: afirmação de uma identidade indígena minoritária ou inserção na identidade nacional? In: FUNARI, Pedro P.A., ORSER JR., Charles E. \& SCHIAVETTO, Solange N.O. Identidades, discurso e poder: estudos da Arqueologia Contemporânea. Fapesp/Annablume, p. 77-90, 2005.

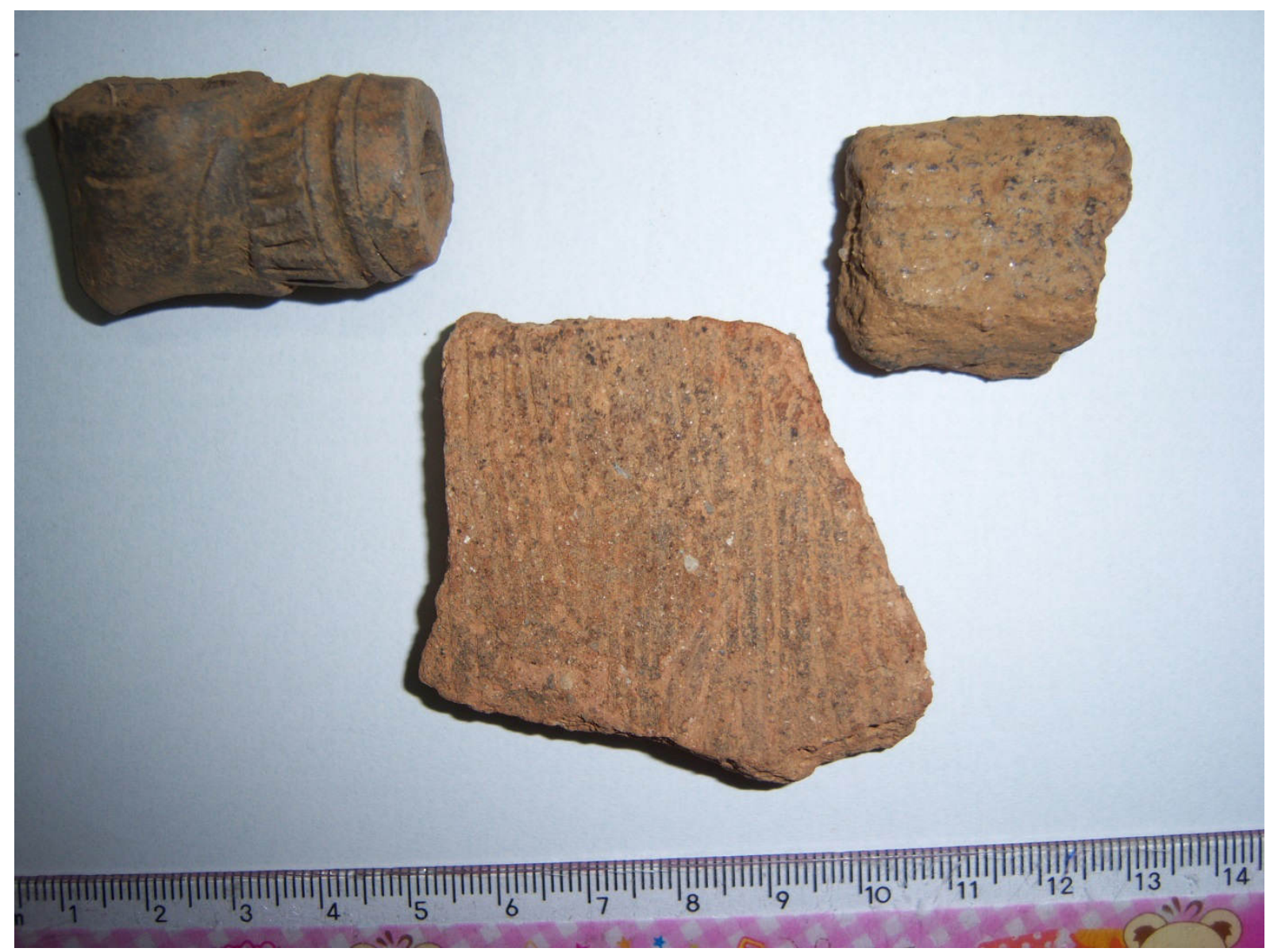

Material cerâmico encontrado em sítio arqueológico em Caldas/MG. Foto: Solange Schiavetto. 